\title{
FEDERALISMO, ASSIMETRIA E SUBSIDIARIEDADE: PARADIGMAS PARA A PROMOÇÃO DO DESENVOLVIMENTO NACIONAL
}

\author{
Flávio Pansieri ${ }^{1}$ \\ Kamar Haddad Netto ${ }^{2}$
}

\begin{abstract}
RESUMO: O presente artigo tem por objetivo analisar o federalismo jurídico assimétrico e o princípio da subsidiariedade como paradigmas para a promoção do desenvolvimento nacional. Mediante o método do raciocínio dedutivo-argumentativo, as modificações nas competências dos entes federados e a forma de seus exercícios, assim como a celebração de negócios jurídicos de cooperação e a evolução na jurisprudência serão apontados como formas de concretizar os pilares teóricos da assimetria e da subsidiariedade, de forma a otimizar a organização políticoadministrativa brasileira.
\end{abstract}

PALAVRAS-CHAVE: Federalismo. Assimetria. Subsidiariedade. Desenvolvimento nacional.

SUMÁRIO: 1. Introdução. 2. Federalismo e assimetria: breves apontamentos conceituais. 3. O princípio da subsidiariedade na organização do Estado Federal. 4. Federação (juridicamente) assimétrica e subsidiária: operacionalização dos paradigmas para a promoção do desenvolvimento nacional. 5. Conclusão. 6. Referências.

\section{FEDERALISMO, ASIMETRÍA Y SUBSIDIARIEDAD: PARADIGMAS PARA LA PROMOCIÓN DEL DESARROLLO NACIONAL}

RESUMEN: Este artículo tiene como objetivo analizar el federalismo asimétrico jurídica y el principio de subsidiariedad como paradigmas capaces de estimular el desarrollo nacional. Por el método de razonamiento argumentativo deductiva, los cambios en los poderes de las entidades federales y la forma de su ejercicio, así como la ejecución de la cooperación jurídica y desarrollo de negocios bajo la ley brasileña serán destacados como formas de lograr los pilares teóricos de asimetría y subsidiariedad, con el fin de optimizar la organización política y administrativa de Brasil.

\footnotetext{
${ }^{1}$ Pós-doutor em Direito (USP). Doutor em Direito (UFSC). Mestre em Direito (USP). Conselheiro Federal da Ordem dos Advogados do Brasil. Vice-Presidente da Comissão Nacional de Estudos Constitucionais do Conselho Federal da OAB. Presidente do Conselho Fundador da Academia Brasileira de Direito Constitucional ABDConst. Professor de Direito Constitucional da Pontifícia Universidade Católica do Paraná. Sócio do escritório Pansieri \& Campos Advogados. Pontifícia Universidade Católica do Parana (PUCPR) - Brasil. Lattes: http://lattes.cnpq.br/0746109917958819 E-mail: pansieri@pkc.adv.br

${ }^{2}$ Graduado em Direito pelo Centro Universitário Curitiba (2010-2014). Especialista em Direito Constitucional pela Academia Brasileira de Direito Constitucional (2015-2016) e em Direito Penal pela mesma instituição (20162017). Centro Universitário Curitiba - Brasil. E-mail: kamarnetto@gmail.com
} vol.12,nº4, Riode Janeiro, 2019.pp. 88110 
PALAVRAS CLAVE: Federalismo. Asímetria. Subsidiariedad. Desarrollo nacional.

CONTENIDO: 1. Introducción. 2. Federalismo y asimetría: breves notas conceptuales. 3. El principio de subsidiariedad en la organización del Estado Federal. 4. Federación (jurídicamente) assimétrica y subsidiaria: operacionalización de los paradigmas para la promoción del desarrollo nacional. 5. Conclusión. 6. Referencias.

\section{INTRODUÇÃO}

Expressamente previsto como um dos objetivos fundamentais da República brasileira, a promoção do desenvolvimento nacional - aqui compreendido como o desenvolvimento multifatorial de ordem econômica, individual, social, cultural e política - pode ser considerada como uma das finalidades mais íntimas do Estado contemporâneo. Dada a complexidade que permeia as funções da figura estatal orientada pelo viés desenvolvimentista, abordar-se-á de forma específica os paradigmas do federalismo juridicamente assimétrico e do princípio da subsidiariedade como vetores capazes de reorientar a organização político-administrativa da República Federativa brasileira, tornando-a mais eficaz na persecução dos comandos insculpidos no artigo $3^{\circ}$, de sua Constituição de 1988.

Ambos paradigmas - assimetria e subsidiariedade - serão apresentados como alternativas à tendência centralizadora fortemente enraizada na história do constitucionalismo brasileiro. Os benefícios para a proteção das liberdades individuais; a maior eficiência na garantia dos direitos fundamentais de ordem social; e os reflexos democráticos serão evidenciados como resultados claros diante da adoção destes motores de promoção ao desenvolvimento nacional.

Para além das premissas teóricas, apontar-se-á, ainda que de forma sucinta, alguns instrumentos de operacionalização dos racionais anteriormente expostos, a exemplo das alterações quanto às competências legislativas e administrativas previstas constitucionalmente, a celebração de negócios jurídicos de cooperação entre os entes federados, e, também, uma breve crítica à interpretação que sempre foi conferida ao denominado princípio da simetria pelo Supremo Tribunal Federal.

Por meio de um procedimento metodológico de raciocínio dedutiva-argumentativo, o presente trabalho pretende demonstrar que o desenvolvimento nacional brasileiro pode ser 
beneficiado pelas premissas teóricas do federalismo jurídico assimétrico e do princípio da subsidiariedade aplicado à organização do Estado Federal, corroborando com formas de materialização destes pilares teóricos.

\section{FEDERALISMO E ASSIMETRIA: BREVES APONTAMENTOS CONCEITUAIS}

Não há como negar a complexidade normativa decorrente da forma federativa de organização do Estado. Os mecanismos, as técnicas e as regras de construção jurídico-política devem harmonizar, pelo menos, dois ordenamentos distintos, referentes à União e aos respectivos Estados-federados - ou mesmo três órbitas distintas, como adotado pelo artigo 18, da Constituição brasileira de $1988^{3}$, a qual consagra os Municípios como entes federativos autônomos.

Com efeito, a distribuição de competências e atribuições de cada ente federativo desafia mesmo o mais criativo dos constituintes: a coexistência de diferentes polos de tomadas de decisões - os quais necessariamente deverão permanecer unidos, mas, ao mesmo tempo, respeitando as diversidades de cada qual - pode ser considerado um dos principais desafios da arquitetura estatal contemporânea (HORTA, 1985, p. 19-22).

É neste contexto de unidade e diversidade como conceitos simultaneamente contrapostos, mas simbióticos, que parcela da doutrina identificou a ferramenta da assimetria jurídica como método eficaz de organização do Estado Federal, visando a persecução dos objetivos fundamentais de cada sociedade.

Consoante aponta Charles Tarlton (1965, p. 861), historicamente, as análises sobre o Estado Federativo têm prevalecido a reconhecer e a impor um viés formal, que se socorre de um tratamento igualitário e homogêneo para todos os entes federados, independentemente das diferenças fáticas vivenciadas por cada região de um mesmo território. Assim, cegos pela ideia de que nenhum ente federativo deve receber privilégios em relação aos demais, o federalismo simétrico jurídico impõe um modelo que não se mostra capaz de solucionar as dificuldades locais e regionais de seu respectivo Estado.

A ideia de assimetria aplicada ao federalismo decorre de uma divisão inicial básica entre assimetrias fáticas e assimetrias jurídicas: enquanto as primeiras dizem respeito às diferenças que existem no plano da realidade vivenciado por uma determinada sociedade - como as diferentes culturas arraigadas em um mesmo país, ou os abismos socioeconômicos vivenciados por ele -, a

\footnotetext{
3 Art. 18. A organização político-administrativa da República Federativa do Brasil compreende a União, os Estados, o Distrito Federal e os Municípios, todos autônomos, nos termos desta Constituição.
} 
assimetria de direito está diretamente relacionada ao tratamento jurídico destinado à organização federativa de um determinado Estado (RAMOS, 2000, p. 64-65).

O federalismo assimétrico, portanto, pode ser analisado sob a ideia de uma forma de Estado a qual compreende que as diferenças fáticas demandam distintas soluções jurídicas, na medida em que cada região contemplará instrumentos e ferramentas diversas, conforme e na medida de suas necessidades; trata-se, em outras palavras, de reconhecer que os entes federados que integram uma mesma união não possuem idênticas condições e idênticas preocupações, seja entre si, seja entre a federação como um todo (BURGESS, 2006, p. 213).

É incontestável que o tratamento isonômico formal-jurídico vem prevalecendo no federalismo brasileiro; da mesma forma, é irrefutável que este modelo não atende aos objetivos fundamentais insculpidos no artigo $3^{\circ}$, da Constituição Federal de 1988: as diferenças socioeconômicas que atingem o território brasileiro persistem mesmo após décadas e décadas de luta pela maior isonomia entre as diferentes regiões do Brasil. Embora a perfeita igualdade fática não passe de uma utopia, a federação brasileira falha dia após dia em tornar o país mais justo e solidário.

Em decorrência desta flagrante incapacidade de o federalismo juridicamente simétrico auxiliar na solução das diferenças regionais que existem no Estado brasileiro é que surge a oportunidade de melhor explorar os instrumentos de assimetria jurídica, sejam aqueles já normatizados pelo ordenamento jurídico pátrio, sejam os que serão eventualmente adotados pelas técnicas legislativas e administrativas de Estado e de governo.

Em abono a este ponto, cite-se passagem de Dircêo Torrecillas Ramos (2000, p. 59-60), o qual expressamente aponta as experiências internacionais e a necessidade de correção deste defeito:

No Estado federal cada ente recebe as tarefas e recursos para a execução das mesmas. Quando ocorre o desequilíbrio entre as obrigações e os meios financeiros, chegamos ao que se convencionou chamar de crise de sobrecarga. Verificamos que uma das razões para o sucesso do federalismo é um balanceamento geográfico, do tamanho do Estado, da riqueza, da população. No Brasil há uma disparidade em relação a esses requisitos, com acentuada desigualdade. Surge aí a necessidade de corrigir o defeito. A solução encontrada, não só entre nós, mas já preocupando outros países como a Suíça, Espanha, Estados Unidos, é a busca do equilíbrio, a cooperação, através de: a) divisões regionais, por grupos de Estados; b) divisão de tributos; c) criação de incentivos ficais ou outras modalidades e a redistribuição de receitas [...] estes arranjos são o que chamamos de federalismo assimétrico.

Assim, não parece exagero afirmar, como faz parcela da doutrina (MINHOTO, 2015, p. 201-209), que o futuro do federalismo reside na valorização da autonomia dos entes federados, em 
contraponto à tendência centralizadora outrora compreendida como essencial para a manutenção do vínculo do Estado Federal.

\section{O PRINCÍPIO DA SUBSIDIARIEDADE NA ORGANIZAÇÃO DO ESTADO FEDERAL}

Ao lado da assimetria jurídica, há outro princípio que vem sendo investigado como capaz de racionalizar e otimizar a organização político-administrativa do Estado federal: trata-se do princípio da subsidiariedade, o qual pode ser diretamente vinculado ao conceito de federação e do exercício da (des)centralização.

Embora possam ser destinadas diferentes semânticas ao referido princípio, a atuação subsidiária do poder estatal é comumente associada a duas diferentes perspectivas: de um lado, a ideia de que a sociedade civil e as entidades mais próximas destas (a exemplo das famílias e outras organizações não-governamentais) devem ser privilegiadas na solução dos problemas, exceto quando não possuírem capacidade para tanto, hipótese em que as entidades estatais deverão auxiliar aquelas, no que se denomina de aspecto horizontal da subsidiariedade; e, de outro, a perspectiva que a distribuição de competências entre os entes federados deve apoiar-se verdadeiramente no princípio da predominância do interesse (MIRANDA, 2015, p. 129), de forma com que a excessiva centralização seja afastada, representando o seu aspecto vertical. Em síntese, pode-se afirmar que o princípio da subsidiariedade preconiza que "as decisões devem ser tomadas em seu nível mais eficiente" (BIELIAUSKAITÈ, 2012, p. 234).

A semelhança entre os ideais do federalismo e da subsidiariedade certamente não pode ser entendida como completa confusão entre os conceitos. Sobre a sutil - porém relevante - distinção, George Bermann (1994, p. 404) sustenta que a distinção entre federalismo e subsidiariedade está exatamente na forma pela qual os referidos conceitos se relacionam com as competências e atribuições. Enquanto o federalismo é responsável pela distribuição de competências em si - isto é, a grosso modo, não há Federação se não houver ao menos dois níveis políticos distintos -, a subsidiariedade diz respeito à forma de execução das competências previamente estabelecidas: por esta razão, esta última traz consigo uma carga valorativa muito mais acentuada, considerando que é utilizada como balança para avaliar como uma atribuição já existente deverá ser manejada (MARTÍNEZ, 2004, p. 800). Aliás, a própria subsidiariedade não se contrapõe a outros princípios inerentes à organização político-administrativa, como o princípio da especialidade ou da prevalência do interesse local, pois aquela diz respeito tão somente à execução, e não à atribuição, de competências destinadas aos entes federados (BARACHO, 1995, p. 36). 
Além dos referidos aspectos horizontal e vertical do princípio da subsidiariedade, há outras duas dimensões essenciais para a compreensão de seus fundamentos: as suas vertentes negativa e positiva.

Sob a vertente negativa, o princípio da subsidiariedade restringe a tanto intervenção do Estado na esfera dos indivíduos (aspecto horizontal), assim como limita a intromissão de uma entidade federativa de nível superior em outra de nível inferior (aspecto vertical - VISCHER, 2001, p. 118); destarte, sob esta ótica, o intervencionismo somente deverá ocorrer se o resultado por ele obtido, no mesmo cenário, for mais eficiente que a sua abstenção (PORTUESE, 2010, p. 246; CARRERA, 1994, p. 784).

A vertente positiva, por sua vez, recomenda que a atuação do Estado - seja em relação aos indivíduos e às entidades intermediárias, ou seja em relação a um ente federada que está em nível superior ao outro - somente deve ocorrer com a finalidade de prestar auxílio na execução de um objeto, sem que se promova uma completa substituição das responsabilidades pela persecução da finalidade pretendida (VISCHER, 2001, p. 118-119). Considerando a vertente da análise econômica do direito, a dimensão positiva do princípio da subsidiariedade seria responsável por orientar o ente estatal somente atuar quando de sua conduta resultasse um produto mais eficiente do que a sua abstenção (PORTUESE, 2010, p. 246).

Por estas razões, evidentemente, o princípio da subsidiariedade não é meramente devolutivo: ainda que seja utilizado com frequência para deslegitimar a intervenção estatal, e, consequentemente, ampliar a liberdade e autonomia dos níveis inferiores, é evidente que a sua vertente positiva impõe um ideal de auxílio, e não de abandono. Ao contrário do que pretendem sustentar alguns, o princípio da subsidiariedade pode ser utilizado para justificar tanto uma progressiva centralização quanto uma maior descentralização, conforme a tomada de decisões evoluir em sua eficiência (PORTUESE, 2010, p. 232).

Em que pese a solidez teórica do princípio da subsidiariedade, a sua aplicação não é tarefa simples, especialmente porque não encontra contornos perfeitamente delineados em abstrato: conforme acentua o jurista francês Aurélian Portuese, as incertezas decorrentes da aplicação do princípio da subsidiariedade resultam em uma denominada ambivalência econômica, considerando que o uso do princípio pode resultar tanto em uma excessiva restrição da autonomia de um ente federado (decorrente de uma centralização abusiva), quanto no auxílio ineficaz prestado pela entidade federativa em nível superior, hipótese na qual se configurará o abandono do poder local ou regional e a consequente falha na prestação do serviço pretendido, face a descentralização desarrazoada. Diante desta impossibilidade em se definir ex ante o correto âmbito de aplicação do princípio da subsidiariedade, o referido professor acentua a extrema relevância em avaliar, 
conforme o caso concreto, o melhor método para o seu manejo, considerando que "only a casuistic approach may define the principle of subsidiarity" (PORTUESE, 2010, p. 234).

Naturalmente, o prisma da eficiência utilizado para a aplicação do princípio da subsidiariedade conforme as hipóteses fático-concretas podem resultar tanto em benefícios quanto em prejuízos, a depender da forma de sua aplicação. Ainda que de forma sucinta, cabe apontar algumas das possíveis (des)vantagens decorrentes da instrumentalização do princípio da subsidiariedade no exercício das competências previstas em um Estado Federal.

Em primeiro lugar, pode-se apontar um beneficio democrático em decorrência da racionalização do exercício das competências político-administrativas de um determinado ordenamento jurídico. Esta afirmação resulta da clara aproximação entre subsidiariedade e democracia: ao impor que uma competência seja exercida pelo poder mais próximo dos cidadãos que por ela serão afetados, privilegia-se um maior grau de legitimidade representativa, considerando que o governante mais próximo do indivíduo será responsável por materializar a previsão normativa; evita-se a concentração de poderes, eis que diferentes polos de tomada de decisões são recrutados, em detrimento de uma excessiva centralização em um único representante; da mesma forma, possibilita-se maior controle da eficácia e eficiência da decisão tomada; e estimula-se a diversidade e a pluralidade, pois as escolhas locais permitem maior heterogeneidade que aquelas decorrentes de uma escolha centralizada (ZIMMERMANN, 2014, p. 87-89).

Deste mesmo benefício também decorre a proteção do indivíduo contra as eventuais arbitrariedades provocadas pelo governo: ao separar estes em diferentes níveis, e ao aproximar os centros de tomadas de decisões dos cidadãos que respectivamente os elegeram, surge uma nova camada de proteção dos direitos fundamentais individuais, como já era reconhecido pelos textos publicados sob a denominação de Federalist Papers, especialmente o ${ }^{\circ} 51$.

A descentralização racionalizada pela subsidiariedade também possibilita um beneficio de eficiência, pois "local governments can more efficiently provide goods to local publics than central governments can" (PORTUESE, 2010, p. 235). O racional desta argumentação reside em diferentes fundamentos, mas o principal deles está relacionado às diferenças e às diversidades que existem ao longo de um mesmo território nacional - a título de exemplo, embora os problemas do sistema educacional brasileiro atinjam toda a nação, é evidente que há um abismo entre as diferentes regiões deste país com proporções continentais. Destarte, embora o problema possua uma abrangência nacional, as diversidades regionais e locais demandam que diferentes técnicas e soluções sejam adotadas conforme as especificidades de cada casa concreto.

Esta relação existente entre a diversidade dos problemas e a necessidade de adoção de soluções específicas também pode ser atacada pela correta aplicação do princípio da 
subsidiariedade, e, consequentemente, pela correta descentralização do exercício de competências constitucionais, se se considerar que estas técnicas permitem que os agentes econômicos descubram os melhores planejamentos, regulações e condutas para satisfazer as necessidades locais e regionais, tanto em termos formais quanto substanciais (PORTUESE, 2010, p. 238-239).

Em outras palavras, a descentralização e a subsidiariedade permitem que o sistema federativo funcione como um verdadeiro laboratório de experiências: ao permitir que uma determinada atividade seja materializada apenas em um local - ao invés de impô-la como política nacional -, possibilita-se, a uma, que eventuais resultados positivos sejam adaptados e incorporados por outras regiões com questões similares; e, a duas, que eventuais falhas na política pública selecionada causem danos limitados e reduzidos a uma determinada esfera territorial (a qual democraticamente elegeu representantes com aquela respectiva agenda política), sem colocar todo o território nacional em risco (OATES, 1999, p. 87).

Entretanto, como assinalado anteriormente, o uso do princípio da subsidiariedade não é isento de riscos e possíveis prejuízos à organização político-administrativa de um dado território.

O primeiro flagrante problema decorre, sem sombra de dúvidas, de um frenesi descentralizador que por vezes acompanha a aplicação do referido princípio. Sob o já mencionado aspecto horizontal da subsidiariedade, eventual deturpação do conceito pode resultar em uma excessiva retirada de poderes do Estado, transferindo-os para os cidadãos e as entidades intermediárias, os quais se tornarão incapazes de atender a todas as atribuições que lhes forem acometidas, criando uma nítida hipótese de abandono estrutural, e não de mera atuação subsidiária. O mesmo raciocínio pode ser aplicado para o aspecto vertical: a transferência do exercício de uma competência de um ente federativo de nível superior para outro de nível inferior (por exemplo, a completa municipalização de um problema flagrantemente estadual) claramente resultará em uma hipótese na qual a adversidade agravar-se-á ainda mais (VISCHER, 2001, p. 129-131).

Embora a excessiva centralização seja uma resposta indesejada, é evidente que o seu oposto - a excessiva descentralização - não pode ser encarada de outra forma. Com efeito, a correta centralização pode acarretar em vantagens decorrentes da harmonização de dispositivos legais e no estabelecimento de padrões de conduta. A ideia de que todos os entes federativos atuarão sempre de forma cooperativa é, evidentemente, uma utopia; também o é a ideia de que todas as entidades federativas sempre estarão de pleno acordo com as políticas adotadas por esferas centralizadas. Ao contrário, a realidade demonstra que, assim como ocorre no plano individual, as organizações políticas tendem a agir com tendências individualistas, ainda que a custo dos interesses alheios. Neste contexto, ainda que a aquiescência de todos os envolvidos seja ilusória, a obtenção de uma maioria - pautando-se por critérios de eficiência e legitimidade, tais como o de Pareto ou o de 
Kaldor-Hicks - possibilita que as minorias discordantes, em certas hipóteses, sejam forçadas a trabalhar de forma cooperada e em prol do bem comum (PORTUESE, 2010, p. 239-241).

Outros benefícios relacionados à centralização podem ser encontrados na literatura especializada, a exemplo da correção do viés da informação: embora os níveis locais e regionais estejam mais próximos de seus problemas, há, ao mesmo tempo, uma impossibilidade destes visualizarem o aspecto global das adversidades que os atingem. A função da entidade central, neste cenário, é racionalizar e otimizar as eventuais soluções a serem adotadas, especialmente diante destas hipóteses nas quais o acesso à informação e à totalidade do problema é limitada pelo estados e municípios. Uma conduta decorrente da entidade central, a qual se tornará responsável por organizar e coordenar a resposta a ser dada ao problema, possibilita que resultados superiores sejam obtidos em relação àqueles decorrentes de uma conduta isolada (VISCHER, 2001, p. 138).

Em síntese, é possível apontar que o princípio da subsidiariedade possui uma dupla função: de um lado, este conceito impõe o respeito às liberdades (autonomia) dos membros integrantes de um determinado polo social ou político; de outro, sabendo-se que uns serão mais vulneráveis que outros, impõe a cooperação (solidariedade) para que as adversidades sejam superadas por uma atuação conjunta. Em outras palavras, embora o princípio da subsidiariedade reconheça o direito de os indivíduos adotarem condutas que melhor se adequem as suas liberdades, o mesmo conceito não afasta o reconhecimento de que as unidades sociais e governamentais existem, cabendo a elas cooperar em prol do desenvolvimento conjunto (BIELIAUSKAITÈ, 2012, p. 242).

É esta função de solidariedade que impede o manejo da subsidiariedade como justificativa para uma descentralização ou abandono estrutural desenfreados, especialmente no contexto do Estado contemporâneo multifuncional, em que diferentes competências são distribuídas conforme a capacidade de cada esfera territorial melhor executá-las em prol do bem comum (VISCHER, 2001, p. 116).

Em relação a esta função de resgate decorrente do princípio da subsidiariedade, Robert Vischer (2001, p. 119) assevera que:

The principle underlying subsidiarity thus stated is that a society is more just and more functional if the work that can be done by the parts is done by the parts, rather than being taken over by the whole. The responsability of the state in this sphere is to assist the subsidiary groups in achieving their proper ends, and to implement those ends itself only temporarily in circumstances where the subsidiary group is, perhaps because of particular socio-economic conditions, incapable of functioning normally. This second aspect of subsidiarity involves the state intervening - but temporarily and in limited fashion - to secure the goods of the partial community, but only so long as the partial community is incapable of achieving its ends. Hence the state's intervention should aim at helping the subsidiary group regain the capacity to function for itself. 
Como se vê, a frequente assimilação da ideia de subsidiariedade com a de uma situação de "quase abandono" não se justifica. Sua função tutelar - a qual inclusive está inserida em sua própria semântica - é tão relevante quanto a sua função libertária, pois não há liberdade onde inexiste condições mínimas socioeconômicas; não há autonomia onde há abandono; e, por isso, não pode a subsidiariedade servir de justificativa (ilegítima, obviamente) para eximir uma entidade federativa de socorrer outra. A função desenvolvimentista do princípio da subsidiariedade é defendida com veemência pelo jurista italiano Edoardo Tommaso Frosini (2002, p. 23), para quem o referido princípio deve "conseguir la remoción de los obstáculos de orden económico y social que limitando de hecho la libertad e igualdad de los ciudadanos, impiden el pleno desarollo de la persona humana".

Em síntese, a íntima proximidade entre subsidiariedade, reciprocidade, solidariedade e auxílio (ORNAGHI, 2012, p. 33; COLOMBO, 2012, p. 30) não pode ser negada. Agir subsidiariamente não significa apenas abster-se de intervir, ou privilegiar a autonomia; significa, também, socorrer e resgatar quando assim for necessário - não se trata, em outras palavras, de um princípio meramente devolutivo ou descentralizador.

Com estas premissas estabelecidas para o princípio da subsidiariedade - isto é, que se trata de um fundamento legítimo para a promoção da liberdade e da solidariedade, conforme exigir o caso fático -, em nítida aproximação das raízes do federalismo assimétrico, resta demonstrar como estas linhas teóricas podem ser, ao menos de forma inicial, operacionalizadas pela organização político-administrativa brasileira.

\section{FEDERAÇÃO (JURIDICAMENTE) ASSIMÉTRICA E SUBSIDIÁRIA: OPERACIONALIZAÇÃO DOS PARADIGMAS PARA O DESENVOLVIMENTO NACIONAL BRASILEIRO}

Já se adiantou que o federalismo brasileiro necessita de doses de assimetria jurídica e de subsidiariedade para que caminhe em direção de uma progressiva simetria fática. Com efeito, ao mesmo tempo em que não se nega a existência de benefícios decorrentes do movimento centralizador, afigura-nos que, historicamente, a descentralização e a subsidiariedade sempre foram desproporcionalmente abandonadas pelo Estado brasileiro.

Em atenção à evolução histórica, precisa as lições de Clèmerson Merlin Clève e Pedro Henrique Gallotti Kenicke (2015):

A história constitucional do país apresenta momentos de tensão e distensão entre os entes federados, tendo sido a centralização manejada, com frequência, para 
justificar uma organização estatal comum e permitir a modernização da sociedade e a racionalidade das ações estatais. É preciso pensar se não estamos indo, agora, longe demais. Não bastassem as várias Emendas à Constituição transferindo competências estaduais para a União, vemos, nos últimos anos, atos normativos baixados pelo Poder Executivo, leis federais e decisões do Supremo Tribunal Federal contribuindo para o preocupante robustecimento do processo. É oportuno lembrar que a divisão espacial de poder não supõe apenas forma de racionalização das tarefas estatais. Mais do que isso, a divisão espacial do poder, assim como a orgânica, substancia mecanismo valioso de controle do poder e veículo de manifestação da liberdade de associação política dos cidadãos. O Estado é, e deve ser, antes de tudo, uma associação política entre cidadãos livres e iguais. Sendo assim, quanto mais próximo está o cidadão do poder, mais ativa se apresenta a cidadania. O Brasil de hoje parece estar se esquecendo desta lição.

Com efeito, esta desarrazoada concentração de poderes na esfera federal, em detrimento dos demais entes federados, parece ser um relevante obstáculo à promoção do desenvolvimento nacional brasileiro - há de se apontar que esta tendência centralizadora, como bem exposto pelos autores anteriormente mencionados, foi mantida por posicionamentos dos Poderes Executivo, Legislativo e, inclusive, do Judiciário, pois análise da jurisprudência do Supremo Tribunal Federal "revela que, ao invés de buscar um ponto médio para maior equilíbrio entre as unidades federadas, a Corte contribui para a hegemonia da União, em detrimento dos Estados" (MELLO, 2011, p. 4).

Estas disfunções do federalismo brasileiro extrapolam o âmbito da definição e do exercício das competências constitucionais desenhadas para os entes federados.

$\mathrm{Na}$ esfera tributária e financeira, por exemplo, há evidentes problemas que afligem a Federação brasileira. O exercício da competência legislativa tributária plena, pela esfera federal, não raramente, esvazia por completo a competência suplementar dos Estados-federados; a superioridade da União na criação de tributos - de natureza fiscal e extra fiscal - e de contribuições dificultam ainda mais a situação econômica dos demais entes federados; e, embora o último texto constitucional tenha evoluído o financiamento dos municípios, a dependência destes dos repasses promovidos pela esfera federal, a exemplo do Fundo de Participação dos Municípios, e os inúmeros escândalos de corrupção que atingem este sistema reforçam ainda mais as dificuldades do abastecimento financeiro das entidades federativas (LINO; MACHADO, 2015, p. 122-127).

Como mencionado anteriormente, embora a centralização não possa se tornar sinônimo de uma medida inerentemente negativa, não há dificuldades em se reconhecer que o federalismo brasileiro - mediante atuação conjunta de seus três Poderes - ultrapassou os limites do razoável e estimulou uma concentração excessiva e disfuncional de competências e poderes na esfera federal.

Os paradigmas da assimetria jurídica e do princípio da subsidiariedade descritos anteriormente sobressaem, neste contexto, como prováveis soluções adequadas para a Federação brasileira. 


\title{
4.1. Readequação das competências constitucionais e efetivo exercício das competências delegadas e concorrentes
}

A primeira das mudanças que visam uma evolução do federalismo brasileiro está diretamente relacionada à noção de assimetria jurídica: considerando que uma simples leitura dos dispositivos constitucionais referentes à organização político-administrativa do Brasil permite reconhecer a notória concentração das mais relevantes competências na esfera federal, uma primeira alteração poderia partir da promulgação de emendas constitucionais que redistribuíssem parcela das atribuições para os demais entes federados.

Com efeito, em relação ao desequilíbrio federativo decorrente do desenho institucional brasileiro, Alexandre de Moraes (2009, p. 9) assevera que:

\begin{abstract}
Se, teoricamente, a Constituição republicana de 1988 adotou a clássica repartição de competências federativas, prevendo um rol taxativo de competências legislativas para a União e, dessa forma, mantendo os poderes remanescentes dos Estados membros; na prática não se verifica tal equilíbrio, exatamente, pelas matérias descritas no art. 22 do texto constitucional e pela interpretação política e jurídica que tradicionalmente se dá ao art. 24. Ao verificarmos as matérias do extenso rol de 29 incisos e um parágrafo do art. 22 da $\mathrm{CF} / 88$, é facilmente perceptível o desequilíbrio federativo no tocante à competência legislativa entre União e Estados membros, uma vez que há a previsão de quase a totalidade das matérias legislativas de maior importância para a União [...] Além da tradicional interpretação política e jurídica que vem sendo dada ao art. 24 do texto constitucional, no sentido de que, nas diversas matérias de competência concorrente entre União e estados, a União pode discipliná-las quase integralmente, temos o resultado da diminuta competência legislativa dos Estados membros, gerando a excessiva centralização nos poderes legislativos na União, o que caracteriza um grave desequilíbrio federativo.
\end{abstract}

Embora nos pareça que um rearranjo político-administrativo a ser promovido formalmente no texto constitucional brasileiro seja uma das saudáveis opções a ser adotada pela Federação brasileira, é evidente que se trata de uma solução com inúmeros obstáculos a ser superados, inclusive de ordem política, dada a celeuma existente quanto à distribuição de competência entre as entidades federativas pátrias.

Uma solução de mesmo estatura, mas que poderia aproveitar dos dispositivos constitucionais já existentes, seria o adequado exercício das competências concorrentes e delegadas, respeitando-se o a esfera de autonomia dos Estados-federados e dos Municípios, e assegurando-lhes liberdade e recursos para que solucionem, com eficiência e respaldo democrático, os problemas locais. Note-se que há uma evidente aproximação desta solução com a aplicação do princípio da subsidiariedade na organização do Estado federal. 
Esta busca por um exercício mais equânime das competências político-administrativas previstas na Constituição Federal de 1988 poderia pautar-se, por exemplo, por um agir da União mais respeitoso com os Estados-federados quando do exercício de competências concorrentes, mediante uma postura restritiva quanto à edição de normas gerais, de forma a deixar espaço relevante para a atuação estadual; o maior zelo no exercício de suas atribuições privativas, levandose em consideração que o texto constitucional, como dito anteriormente, atribui-lhe significativa preponderância no desenho federativo nacional; e maior cuidado no exercício das competências financeiras e tributárias, considerando que a União também é notoriamente privilegiada neste aspecto (MELLO, 2011, p. 20-21).

Sob a ótica da assimetria e da subsidiariedade, estes conflitos de competência não podem ser solucionados pelo critério hierárquico ou vertical - aqui compreendido como aquele critério que entrega o exercício da competência ao ente federado de maior extensão. Antes, há de se considerar a predominância do interesse local, do interesse regional, e da expressa previsão da autonomia federativa entre aos Estados e Municípios, a qual não pode ser soterrada e transformada em letra morta todas as vezes que estas entidades federativas tiverem suas competências políticoadministrativas sopesadas com aquelas desenhadas para a União (DE MORAES, 2009, p. 11).

Além desta posição de deferência para com o exercício das competências dos Estadosfederados e dos Municípios, a União pode adotar postura ativa no combate às desigualdades sociais e econômicas brasileiras, através da possibilidade constitucional aventada no artigo $43^{4}$, o qual certamente ainda possuí amplo espaço para exploração e otimização, considerando que, mesmo de sua redação tímida, ainda não vem sendo aplicado com protagonismo pelos sucessivos governos brasileiros.

\subsection{Cooperação dos entes federados mediante a celebração de negócios jurídicos e a edição de leis complementares cooperativas}

A cooperação das entidades federativas pode ser executada tanto em face da edição de leis complementares quanto mediante a celebração de negócios jurídicos de cooperação, como parcerias ou convênios e consórcios públicos. Tanto em um quanto em outro caso, há expresso fundamento

\footnotetext{
${ }^{4}$ Art. 43. Para efeitos administrativos, a União poderá articular sua ação em um mesmo complexo geoeconômico e social, visando a seu desenvolvimento e à redução das desigualdades regionais.
} 
constitucional: tratam-se dos artigos 23, § único ${ }^{5}$, e $241^{6}$, ambos da Constituição Federal de 1988, respectivamente.

A possibilidade de edição de leis complementares visando a fixação de normas cooperativas entre os entes federados brasileiros, para que otimizem a persecução dos objetivos fundamentais da república, não escapa de críticas da doutrina. Há tempos que clássicos e relevantes juristas - a exemplo de Celso Ribeiro Bastos (1992, p. 430) e de Manoel Gonçalves Ferreira Filho (1990, p. 188) - já sustentavam a desnecessidade da previsão que constam do artigo 23 da Constituição Federal de 1988, levando-se em consideração que a cooperação das entidades federativas poderia ser realizada pela celebração de negócios jurídicos cooperativos (os quais, em princípio, são de maior celeridade e simplicidade); e pela cooperação decorrer de um verdadeiro senso cívicopolítico, prescindindo de norma de imposição.

Neste mesmo sentido, parece correta a crítica lançada por José dos Santos Carvalho Filho (2013, p. 7):

\begin{abstract}
A rigor, seria de se indagar sobre a necessidade do dispositivo. Se houvesse consciência cívico-política entre os governantes dos entes federativos, nenhuma razão haveria para conferir à União o poder de estabelecer regras gerais de cooperação, pois que afinal esta nasce do consenso, e não de imposição. A competência outorgada à União demonstra claro intuito de verticalização, retirando aos demais entes a capacidade de sopesar regras contrárias a seus interesses.
\end{abstract}

A celebração de negócios jurídicos de cooperação parece ser um caminho promissor para a atuação conjunta dos entes federados brasileiros.

Historicamente, os consórcios públicos foram firmados a partir da década de 1960, possuindo especial relevância o Consórcio Intermunicipal do Grande $\mathrm{ABC}$, interior do Estado de São Paulo. A partir das décadas de 1980 e 1990, os consórcios foram significativamente focados na área da saúde, sendo que até os dias atuais, esta tende a ser a área de maior concentração de esforços das entidades federativas cooperantes. Fortes evidências estatísticas demonstram que a promulgação da Lei $\mathrm{n}^{\circ}$ 11.107/2005 favoreceu a expansão dos consórcios públicos, seja quanto ao espaço de atuação, seja quanto às ações a eles atribuídos. Com efeito, do ano de 1999 a 2009, o número de consórcios públicos referentes à moradia saltou de 47 para 170 (aumento de

\footnotetext{
${ }^{5}$ Art. 23. § único. Leis complementares fixarão normas para a cooperação entre a União e os Estados, o Distrito Federal e os Municípios, tendo em vista o equilíbrio do desenvolvimento e do bem-estar em âmbito nacional. (Redação dada pela Emenda Constitucional $\mathrm{n}^{\circ} 53$, de 2006)

${ }^{6}$ Art. 241. A União, os Estados, o Distrito Federal e os Municípios disciplinarão por meio de lei os consórcios públicos e os convênios de cooperação entre os entes federados, autorizando a gestão associada de serviços públicos, bem como a transferência total ou parcial de encargos, serviços, pessoal e bens essenciais à continuidade dos serviços transferidos. (Redação dada pela Emenda Constitucional n 19 , de 1998)
} 
aproximadamente $250 \%$ ); de 2.039 para 2.323 (aumento aproximado de $15 \%$, ou praticamente $20 \%$, se considerado que em 2005 houve uma queda para 1.906 consórcios relacionados à prestação de serviços públicos na área de saúde); e de 230 para 398 na área da educação (acréscimo aproximado de 80\%). Embora o referido Diploma Legal não possa ser inteiramente responsabilizado por estes aumentos, trata-se de marco normativo com direta influência no estímulo à celebração de consórcios públicos (LINHARES; CUNHA; FERREIRA, 2016, p. 44).

A figura dos consórcios públicos, aliada de outros negócios jurídicos de cooperação entre os entes federados, é mais um dos paradigmas contemporâneos que podem atingir o objetivo de resgate federativo conforme as necessidades e as realidades de cada região do país; em outras palavras, os negócios jurídicos de cooperação permitem uma articulação capaz de combater a fragmentação - aqui compreendida em um sentido pejorativo - da administração pública brasileira.

\subsection{Revolução do posicionamento jurisprudencial - a questão do denominado princípio da simetria}

Um terceiro aspecto para materializar um federalismo mais justo e funcional passa, necessariamente, por uma verdadeira revolução na jurisprudência brasileira, especialmente quanto à aplicação do denominado princípio da simetria pelo Supremo Tribunal Federal.

Como é cediço, referido princípio não encontra expressa previsão constitucional. Embora o artigo 25 da Constituição Federal de 1988, e o artigo 11 do Ato das Disposições Constitucionais Transitórias, sejam utilizados como permissivos para a aplicação do princípio da simetria, afiguranos simplório que esta criação jurisprudencial não pode ser utilizada para restringir significativamente a autonomia dos Estados-federados e dos Municípios, a qual encontra expressa previsão no texto constitucional. O uso do princípio da simetria, com suas raízes estabelecidas em outra ordem constitucional, parece ter transportado indevidamente para a realidade contemporânea, como bem apontou o então Ministro Sepúlveda Pertence ${ }^{7}$.

Após detida análise da evolução jurisprudencial do mencionado princípio, Clèmerson Clève e Pedro Kenicke (2015) sustentam que "determinadas decisões do Supremo Tribunal Federal tornam, praticamente, sem efeito a autonomia conferida aos Estados pelo Constituinte",

\footnotetext{
7 "Lembro-me de que, na discussão do caso do Amapá, ADIn 1.461, o voto do eminente Ministro Maurício Corrêa, Relator, se fundava exclusivamente no chamado "princípio da simetria". Entendi que esse princípio há de ser encarado cum grano salis. Ele ficou muito presente na jurisprudência do Supremo Tribunal, nos idos de 1967, 1968, quando a Constituição então promulgada limitara os poderes da Assembleia Legislativa, em período certo, aos de adaptar as Constituições Estaduais à nova Constituição da República. Mas, depois, continuou a ser invocado, perdida a sua razão de ser". (Trecho do voto do Min. Sepúlveda Pertence. BRASIL. Supremo Tribunal Federal. Plenário. ADI 3.853/MS. Relatoria: Min. Carmen Lúcia, 12.09.2007. DJe 26.10.2007).
} 
arrematando, com firmeza, que “o STF acaba por cumprir o papel de um 'Guarda da União', ao invés de ser um 'Tribunal da Federação"'.

A crítica quanto à aplicação do princípio da simetria pela jurisprudência pátria também é exposta por Marcelo Labanca Corrêa de Araújo (2010, p. 545):

\begin{abstract}
Pensa-se que deveria haver uma 'regra de ouro' para a utilização do princípio da simetria. Para privilegiar a autonomia dos Estados-membros, a extensão de normas federais pelo princípio da simetria apenas deveria ser realizada quando a não reprodução pudesse afetar a harmonia entre os poderes locais. Ou seja, se há uma estruturação de Poderes e Órgãos estaduais de modo dessemelhante ao modelo federal, mas, mesmo assim, não há qualquer prejuízo para a harmonia entre tais Poderes locais, então entende-se que o princípio da simetria não deve ser aplicado. Caso contrário, aplicar-se-ia o princípio da simetria em tudo, e, consequentemente, a ideia-matriz do federalismo restaria aniquilada no Brasil, já que não haveria identificação de diversidades, em vista da reprodução in totum daquilo que é federal para o plano local.
\end{abstract}

A imposição de uma "cópia da Constituição Federal" aos Estados-federados e até mesmo às Leis Orgânicas dos Municípios tem flagrantes e evidentes efeitos nefastos para a organização federativa brasileira, sendo frequentemente lembrada pela doutrina: anote-se, por exemplo, a opinião de Sahid Maluf (1999, p. 170) neste sentido.

Leonardo Martins (2009, p. 690) também é ferrenho crítico dos efeitos decorrentes da imposição desarrazoada do princípio da simetria ao exercício das competências dos Estadosfederados e dos Municípios:

O que se pretende destacar, portanto, é que antes de ser visto como um fim em si mesmo o federalismo deve garantir, a um só tempo, o direito à diferença e à participação de todos na vontade central. Adotar a forma federativa, pois, não significa impor a estrutura administrativo-organizacional do ente central às entidades parciais. Constitui, sim, garantir que em determinados espaços os estados-membros possam agir com certa margem de liberdade de conformação, sem que disso se depreenda qualquer prejuízo à união indissolúvel preconcebida. Em um país de dimensões continentais, em que cada estado possui necessidades socioeconômicas diversas, e [em] que há enorme variedade cultural, atribuir uma leitura centralizadora ao modelo federativo significa afastar a possibilidade do direito de reduzir as desigualdades sociais e regionais.

Uma simples orientação parece tornar possível adequar o princípio da simetria aos contornos do federalismo adotado pela Constituição brasileira de 1988: bastaria limitar, em princípio, o uso do referido princípio para as normas relacionadas à República Federativa do Brasil em si, afastando-o dos dispositivos concernentes ao ente federado da União, o qual é tão autônomo quanto os Estados e Municípios - a limitação da liberdade político-administrativa destes últimos com base em normas utilizadas para a auto-organização da União seria "negar a própria essência do 
federalismo brasileiro, pois os primeiros seriam tratados como meras divisões administrativas em um Estado Unitário" (DRUMMOND, 2015, p. 136).

Em que pese o histórico jurisprudencial significativamente favorável à aplicação do princípio da simetria na organização federativa brasileira, tem-se notícias de recentes decisões da Suprema Corte que, ao menos em um primeiro momento e felizmente, parecem caminhar para a reversão da tendência, para que se busque uma maior deferência para com a autonomia político e administrativa dos Estados-federados e dos Municípios ${ }^{8}$.

As dificuldades de classificação das matérias constitucionais, e a respectiva conformação com o rol constitucional, portanto, atraem a extrema relevância da jurisprudência, em especial, como dito alhures, da interpretação conferida pelo Supremo Tribunal Federal. Com efeito, também em sede de organização político-administrativa, "o Poder Judiciário possui relevante papel para solucionar dúvidas e afastar interpretações divergentes” (MELLO, 2011, p. 3-4), razão pela qual as melhorias do federalismo brasileiro não se limitam àquelas promovidas pelos Poderes Executivo e Legislativo, devendo igualmente abranger os posicionamentos consolidados pelos Tribunais pátrios (HERMANY, 2012, p. 85-86).

\section{CONCLUSÃO}

A proposta de um "novo" pacto federativo brasileiro, com destaque para as aspas, é justificada. Não se exige maiores esforços para encontrar peculiaridades nos desenhos institucional e político brasileiro; por outro lado, também ficou claro que a atual organização federativa brasileira encontra inúmeras virtudes que certamente não podem ser ignoradas. É por esta razão que o federalismo do Brasil pode, sim, evoluir e ser aprimorado mediante a adoção das linhas da assimetria jurídica, visando uma readequação nas competências constitucionais, e, sob o viés do princípio da subsidiariedade, pode buscar uma aplicação mais justa e solidária da estrutura federativa do Estado brasileiro.

\footnotetext{
${ }^{8}$ A título de exemplo, conferir: Cf.: "A observância da simetria não significa que cabe ao constituinte estadual apenas copiar as normas federais”. (BRASIL. Supremo Tribunal Federal. ADI 253, Tribunal Pleno, Rel. Min. Gilmar Mendes, j. 28.05.2015, DJe 16.06.2015); "Os Estados-membros têm autonomia para definir, nas respectivas constituições, os legitimados para a propositura de ação direta perante o Tribunal de Justiça local, vedada a atribuição de agir a um único órgão". (BRASIL. Supremo Tribunal Federal. ARE 727505 AgR, Primeira Turma, Rel. Min. Marco Aurélio, j. 12.05.2015, DJe 16.06.2015); “A jurisprudência da Corte fixou-se no sentido de que a disciplina acerca da sucessão e da substituição da chefia do Poder Executivo municipal põe-se no âmbito da autonomia política do município, por tratar tão somente de assunto de interesse local, não havendo dever de observância do modelo federal.” (BRASIL. Supremo Tribunal Federal. RE 655647 AgR, Primeira Turma, Rel. Min. Dias Toffoli, j. 11.11.2014, DJe 19.12.2014).
} 
Com precisão, Marco Aurélio Marrafon (2014) sintetiza as orientações pelas quais este "novo" pacto federativo pode ser orientado:

Por essas razões, o novo pacto federativo deve ser baseado no resgate de maior autonomia dos Estados-membros, Distrito Federal e Municípios, aliado à abertura de novos âmbitos de integração democrática com os cidadãos e às estratégias de solidariedade entre os entes, formando o pacto cooperativo, não apenas em sentido formal, mas também material.

As diretrizes para o aprimoramento da organização político-administrativa brasileira, com apoio na lição do referido doutrinador, podem ser assim sintetizadas: deve-se visar a superação dos paradoxos da capacidade e da incapacidade; e perseguir a efetiva cooperação dos entes federados em detrimento do drama do isolacionismo, observando-se o respeito às autonomias de entidade federativa.

Em relação ao paradoxo da incapacidade, Marco Marrafon (2014) o define como aquele em que "quem mais precisa é também quem menos pode", considerando a tendência da Federação brasileira negar auxílio aos entes federados que mais necessitam de apoio; em relação ao paradoxo da capacidade, trata-se da ideia de que "quem pode mais é justamente quem é mais tolhido", considerando as amarras impostas em face das entidades federativas que mais avançam, pois estas são limitadas pelas regras gerais de organização e controle da Administração Pública; e em relação ao drama do isolacionismo, por sua vez, há relação direta com a falta de compartilhamento de experiências entre as entidades políticas integrantes da Federação brasileira - com efeito, o abandono de uns e as liberdades tolhidas de outros parecem ser as raízes dos problemas.

Tratam-se de orientações que em nada destoam das propostas ora defendidas.

A assimetria jurídica certamente auxiliaria na redução dos paradoxos da capacidade e da incapacidade, considerando que uma distribuição mais dinâmica das competências constitucionais evitaria que todos os entes federados estivessem subordinados às mesmas regras, independentemente de suas situações fáticas; a aplicação do princípio da subsidiariedade, a celebração de negócios jurídicos de cooperação, e a evolução jurisprudencial quanto às diretrizes da organização político-administrativa brasileira evidentemente contribuiriam para a superação do drama do isolacionismo, permitindo que as entidades federativas mais necessitadas recebessem o devido auxílio de seus pares, e, ao mesmo tempo, que as esferas mais desenvolvidas fossem desacorrentadas e liberadas das amarras decorrentes de normas de organização e controle gerais, permitindo que promovessem amplas experiências locais e regionais para serem, posteriormente, compartilhadas com os demais Estados-federados e Municípios em situações análogas. 
$\mathrm{O}$ atual desenho federativo e a forma de interpretação e aplicação das competências constitucionais não mais se adequam aos objetivos fundamentais da República. O uso das ferramentas defendidas parece ser adequado para atingir finalidades em diferentes frentes: seja para resgatar as regiões que mais necessitam, seja para liberar os entes federados mais desenvolvidos, os paradigmas da assimetria e da subsidiariedade parecem criar um caminho mais fértil e frutífero para a organização federativa brasileira perseguir o desenvolvimento nacional.

FEDERALISM, ASYMMETRY AND SUBSIDIARITY: PARADIGMS TO SUPPORT THE NATIONAL DEVELOPMENT

\begin{abstract}
This article aims to analyze the asymmetric juridic federalism and the principle of subsidiarity as paradigms capable of stimulate national development. Through the method of deductive-argumentative reasoning, the modifications in the competences of the federated entities and the form of their exercises, as well as the signature of contracts of cooperation, and evolution in the jurisprudence will be pointed out as ways to concretize the theoretical pillars of asymmetry and subsidiarity, in order to optimize the brazilian political-administrative organization.
\end{abstract}

KEYWORDS: Federalism. Asymmetry. Subsidiarity. National development.

SUMMARY: 1. Introduction. 2. Federalism and asymmetry: brief conceptual notes. 3. The principle of subsidiarity in the organization of the Federal State. 4. Federation (juridically) asymmetric and subsidiary: operationalization of paradigms for the promotion of national development. 5. Conclusion. 6. References.

\title{
6 REFERÊNCIAS BIBLIOGRÁFICAS
}

BARACHO, José Alfredo de Oliveira. O princípio de subsidiariedade: conceito e evolução. In: Revista da Faculdade de Direito da Universidade Federal de Minas Gerais, Minas Gerais, n. 35, 1995, p. 13-52.

BASTOS, Celso Ribeiro; MARTINS, Ives Gandra. Comentários à Constituição do Brasil. São Paulo: Saraiva, 1992.

BERMANN, George. Taking Subsidiarity Seriously: Federalism in the European Community and the United States. In: Columbia Law Review. Estados Unidos, v. 94, n. 2, mar. 1994, p. 331-456.

BIELIAUSKAITĖ, Jolanta. The impact of the principle of subsidiarity on the implementation of socio-economic human rights in Lithuania: theoretical aproach. Mykolas Romeris University Publishing. Lituânia, v. 19, n. 1, 2012, p. 231-248.

BURGESS, Michael. Comparative Federalism. New York: Routledge, 2006. 
CARRERA, Angel Boixareu. El principio de subsidiariedad. In: Revista de Instituciones Europeas. Madrid, v. 21, 1994, p. 771-808.

CARVALHO FILHO, José dos Santos. O Município e o enigma da competência comum constitucional. In: Revista Fórum Municipal e Gestão das Cidades. Belo Horizonte, ano 1, n. 1, set./out. 2013, p. 4-25.

CLÈVE, Clèmerson Merlin; KENICKE, Pedro Henrique Gallotti. Federalismo, centralização e princípio da simetria. Consultor Jurídico. São Paulo, dezembro de 2015. Site: $<$ https://jus.com.br/artigos/45081/federalismo-centralizacao-e-principio-da-simetria $>$. Acesso em 25 de janeiro de 2017.

COLOMBO, Alessandro. Principle of Subisidiarity and Lombardy: Theoretical Background and Empirical Implementation. In: COLOMBO, Alessandro (Edit.). Subsidiarity Governance: Theoretical and Empirical Models. Estados Unidos da América: Palgrave Macmillan, 2012.

DE ARAÚJO, Marcelo Labanca Corrêa. Federalismo e princípio da simetria. In: TAVARES, André Ramos; LEITE, George Salomão; SARLET, Ingo Wolfgang (org.). Estado constitucional e organização do poder. São Paulo: Saraiva. 2010.

DE MORAES, Alexandre. Federação brasileira - necessidade de fortalecimento das competências dos estados-membros. In: Revista de Direito Administrativo - RDA, Belo Horizonte, n. 251, maio/ago. 2009, p. 4-19.

DRUMMOND, Marcílio Henrique Guedes. O princípio da simetria no federalismo assimétrico brasileiro. In: Revista Brasileira de Direito Municipal - RBDM, Belo Horizonte, ano 16, n. 58, out./dez. 2015, p. 125-145.

FERREIRA FILHO, Manoel Gonçalves. Comentários à Constituição brasileira de 1988. São Paulo: Saraiva, 1990.

FROSINI, Tommaso Edoardo. Subsidiariedad y Constitución. In: Revista de Estudios Políticos. Espanha, n. 115, jan./mar. 2002, p. 7-25.

HERMANY, Ricardo. (Re)discutindo as políticas públicas no espaço local: interconexões entre federalismo, subsidiariedade e direito social no Brasil. In: MAUÉS, Antonio Moreira (Org.). Federalismo e Constituição. Rio de Janeiro: Editora Lumen Juris, 2012.

HORTA, Raul Machado. Organização Constitucional do Federalismo. In: Revista de Informação Legislativa. Brasília, v. 22, n. 87, jul./set. 1985, p. 5-22.

LINHARES, Paulo de Tarso Frazão Soares; CUNHA, Alexandre dos Santos; FERREIRA, Ana Paula Limna. Federative cooperation: the formation of consortia among public entities in Brazil. In: LINHARES, Paulo de Tarso Frazão; MENDES, Constantino Cronemberger; LASSANCE, Antonio (Edits.). The Brazilian Federalism issues for discussion - dialogues for development. Vol. 8. Brasília: Instituto de Pesquisa Econômica Aplicada, 2016.

LINO, Graziela de Castro; MACHADO, Rodrigo Silveira Diniz. Reflexos das disfunções do federalismo brasileiro na autonomia municipal. In: Revista Brasileira de Direito Municipal RBDM, Belo Horizonte, ano 16, n. 57, jul./set. 2015, p. 122-139. 
MALUF, Sahid. Teoria geral do estado. São Paulo: Saraiva, 1999.

MARRAFON, Marco Aurélio. Novo pacto federativo para aprimorar a democracia brasileira Consultor Jurídico. São Paulo, 21 de abril de 2014. Site: http://www.conjur.com.br/2014-abr21/constituicao-poder-pacto-federativo-aprimorar-democracia-brasileira $>$. Acesso em 25 de janeiro de 2017.

MARTÍNEZ, Luis Miguel Hinojosa. La regulación del principio de subsidiariedad en el tratado constitucional: espejismos y realidades. In: Revista de Derecho Comunitario Europeo, Espanha, vol. 8 , n. 19, set./dez. 2004, p. 787-827.

MARTINS, Leonardo. Limites ao princípio da simetria constitucional. In: SOUZA NETO, Cláudio Pereira; SARMENTO, Daniel; BINENBOJM, Gustavo (coord.). Vinte anos da Constituição Federal de 1988. Rio de Janeiro: Lumen Juris, 2009.

MELLO, Cristiana de Santis M. de F. Federação: é hora de inverter o ônus argumentativo. In: Revista Brasileira de Direito Público - RBDP. Belo Horizonte, ano 9, n. 33, abr./jun. 2011, p. 161-198.

MINHOTO, Antonio Celso Baeta. Para onde vai o federalismo? Notas sobre o que foi e o que poderá vir a ser o Estado Federal. In: Revista de Direito Administrativo, Rio de Janeiro, v. 268, jan./abr. 2015, p. 187-211.

MIRANDA, Jorge. Teoria do Estado e da Constituição. 4. ed. Rio de Janeiro: Forense, 2015.

OATES, Wallace. An Essay on Fiscal Federalism. In: Journal of Economic Literature, vol. 37, n. 3, set. 1999, p. 1120-1149.

ORNAGHI, Lorenzo. Governance and subsidiarity. In: BRUGNOLI, Alberto; COLOMBO, Alessandro (Edit.). Government, Governance and Welfare Reform: Structural Changes and Subsidiarity in Italy and Britain. Reino Unido: Edward Elgar Publishing Limited, 2012.

PORTUESE, Aurélian. The Principle of Subsidiarity as a Principle of Economic Efficiency. In: Columbia Journal of European Law, vol. 17, 2010, p. 231-262.

RAMOS, Dircêo Torrecillas. O Federalismo Assimétrico. 2. ed. Rio de Janeiro: Forense, 2000.

TARLTON, Charles D. Symmetry and Assymetry as Elements of Federalism: a Theoretical Speculation. In: The Journal of Politics. v. 27, $\mathrm{n}^{\circ}$ 1, fev. 1965, p. 861-874.

VISCHER, Robert. Subsidiarity as a Principle of Governance: Beyond Devolution. In: Indiana Law Review, Vol. 35, n. 103, 2001, p. 103-142.

ZIMMERMANN, Augusto. Subsidiarity, Democracy and Individual Liberty in Brazil. In: EVANS, Michelle; ZIMMERMANN, Augusto (Orgs.). Global Perspectives in Subsidiarity. Londres: Springer, 2014. 
Quaestio Iuris

vol. 12,nº.04, Riode Janeiro, 2019. pp. 88-110 DOI: $10.12957 /$ rqi.2019.39629

Trabalho enviado em 23 de janeiro de 2019

Aceito em 06 de fevereiro de 2020 